International Review of Research in Open and Distributed Learning

Volume 21, Number 3

September -2020

\title{
Editorial - Volume 21, Issue 3
}

Constance Blomgren

Associate Editor, Athabasca University

In this issue of $I R R O D L$, we have a robust variety of Research Articles, a substantial Literature Review, and two Notes From the Field. With the effects of the COVID-19 pandemic affecting education at all levels, the editors have experienced a pivot to seeking answers-what are the best practices in distributed and open learning? Researchers and reviewers in our field have experienced a surge in the need for their expertise; our journal has held a unique position of supporting research into online and blended learning and teaching since its inception.

The editors of IRRODL would like to acknowledge the many hours of commitment to the field that our contributors and readers have experienced since the spring of 2020. We commend your professionalism, dedication, and for the work you do in supporting this quick and fierce pivot to online education.

The first of our 15 research articles, "Learners' Perceptions of Online Exams: A Comparative Study in Turkey and Kyrgyzstan," examines online exams. Adanır, İsmailova, Omuraliev, and Muhametjanova studied university students' perceptions according to gender, and major and prior online course experience, in this mixed method study of a timely topic.

Student perceptions of service quality, e-service, and university image were studied by Daud, Amin, and Karim. "Antecedents of Student Loyalty in Open and Distance Learning Institutions: An Empirical Analysis" originates from the Open University of Malaysia.

“Does Delivery Model Matter? The Influence of Course Delivery Model on Teacher Candidates' Self-Efficacy Beliefs Towards Inclusive Practices" examines essential components of online education. The authors Smothers, Colson, and Keown applied a causal-comparative research design to examine the influences of face-to-face flipped or asynchronous online upon self-efficacy beliefs of inclusive learning and teaching.

Doo, Bonk, and Heo completed a meta-analysis regarding the significance of scaffolding in online higher education teaching practices. The results of this study, "A Meta-Analysis of Scaffolding Effects in Online Learning in Higher Education," will be of interest to instructional designers and the many educators who are now pivoting to online education.

MOOCs continue to be of interest to researchers and Lee, Watson, and Watson studied students' selfregulated learning strategies, self-efficacy, and task value on perceived effectiveness in the Mountain 101

MOOC. Read the study's results in “The Influence of Successful MOOC Learners' Self-Regulated Learning 
Strategies, Self-Efficacy, and Task Value on Their Perceived Effectiveness of a Massive Open Online Course."

In the sixth research article, Yang, Su, and Bradley applied Rasch analysis for evaluation and validation of the Self-Directed Online Learning Scale (SDOLS). "Applying the Rasch Model to Evaluate the SelfDirected Online Learning Scale (SDOLS) for Graduate Students” contributes psychometric results toward increasing the reliability and validity of SDOLS.

"An Analysis of Course Characteristics, Learner Characteristics, and Certification Rates in MITx MOOCs" investigates the 122 Massachusetts Institute of Technology MOOCs and the interplay among course and learner characteristics as well as certification results. Celik, Cagiltay, and Cagiltay generated results that point to the importance of interactivity and course content design.

"Evaluation of Student Feedback Within a MOOC Using Sentiment Analysis and Target Groups" involved a dataset of over 25,000 online posts from an introductory computer programming MOOC. The researchers, Lundqvist, Liyanagunawardena, and Starkey applied automated sentiment analysis to assess student experience.

Shadiev, Wang, and Huang designed an intercultural VR learning activity to investigate university students from China and Uzbekistan as part of supporting intercultural competence. "Promoting Intercultural Competence in a Learning Activity Supported by Virtual Reality Technology" examines the role of advanced educational technology as part of emerging cross-cultural teaching practices.

Mobile technology continues to influence how people learn and teach. The article, "Research Trends in Mobile Learning” by Yıldız, Yıldırım, Akça, Kök, Özer, and Karataş provides the trends from 20162019 from 1023 articles-an excellent overview of topics and gaps in the literature for mobile researchers.

Zhang examines the role of emotions regarding the use of open educational resources. He examined students' reflections, group discussions, interviews, and field notes in his study, "Revisiting Textbook Adaption Through Open Educational Resources: An Inquiry into Students' Emotions.”

“A Qualitative Inquiry of K-12 Teachers' Experience with Open Educational Practices: Perceived Benefits and Barriers of Implementing Open Educational Resources" marks the second OER research in this issue. Tang provides his interview results and thus contributes to the growing interest of OER for K-12 education.

"Profiles of Online Students and the Impact of Their University Experience" was a study conducted with students from a fully online institution, Universitat Oberta de Catalunya (UOC). This research by SánchezGelabert, Valente, and Duart indicates that student profiles continue to reflect responsibilities outside of the university but younger students without significant work or family responsibilities are now being observed. 
Dridi, Radhakrishnan, Moser-Mercer, and DeBoer examined the equity issues of education with their study, "Challenges of Blended Learning in Refugee Camps: When Internet Connectivity Fails, Human Connection Succeeds." This important research encountered connectivity issues and other barriers, yet the results point to the resiliency of students, educators and researchers.

Ouyang, Li, Sun, Jiao, and Yao provide the last research article for this issue. "Learners' Discussion Patterns, Perceptions, and Preferences in a Chinese Massive Open Online Course (MOOC)" applies a mixed method approach. The researchers examined how their pedagogical strategy, a learning analytic tool, and social learning interact as part of encouraging MOOC learner discussions.

The Literature Review examines MOOCs for the K-12 sector. Koutsakas, Chorozidis, Karamatsouki, and Karagiannidis fill a niche by locating and summarizing the extant literature of K-12 MOOCs since 2013. Educators and researchers of younger students alike will welcome "Research Trends in K-12 MOOCs: A Review of the Published Literature."

Completing this robust issue are two Notes From the Field. Dennis provides a theoretical discussion of connectivism and the role of language within its conceptualization. Hypertextuality and intertextuality are embedded within network learning and its roots in philosophy. "Languaging Network Learning: The Emergence of Connectivism in Architectonic Thought" contributes to the understanding of connectivism and its influence upon online education.

"Elements of Open Education: An Invitation to Future Research" will be of interest to new researchers and those who are shifting focus. Providing an historical overview of open education, the authors then move to their framework of macro, meso, and micro levels of research in open and distance learning. This cadre of authors include: Zawacki-Richter, Conrad, Bozkurt, Aydin, Bedenlier, Jung, Stöter, Veletsianos, Blaschke, Bond, Broens, Bruhn, Dolch, Kalz, Kondakci, Marin, Mayrberger, Müskens, Naidu, Qayyum, Roberts, Sangrà, Loglo, Slagter van Tryon, and Xiao.

Enjoy this issue.

\section{Athabasca} University

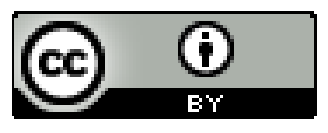

